\title{
Marginality of Rural Migrant Students in Eleven Chinese High Schools
}

\author{
Tao Wang ${ }^{1}$ \\ University of Washington, Seattle, USA
}

\begin{abstract}
Since Chinese economic reform in the 1980s that prompted increased urbanization, gap between rural and urban places continually widen, and obvious cultural differences are observed. Rural students are migrating to heterogeneous urban environments and meet problems of marginality. Perceiving the differences in urban life, these students begin to acquire urbanite and urban cultural personalities. Meanwhile, because of their original lower socioeconomic status, they are caught between rural culture and urban culture, and experience marginality in different ways. The purpose of this study is to elucidate the marginal experience of rural migrant students. Applying surveys, interviews, and observation, this study involved 55 students from 11 urban schools in China. This paper details their marginal experiences in study adaption, life experience, social interaction, relationships, and value.
\end{abstract}

Key Words: Marginality, Rural migrants, Urban Schooling, China

\section{Introduction}

Mass migration became a world phenomenon happing in the last few decades. While there are migrants moving between countries recently, such as immigrants to the United States and refugees to the European countries, mass internal migration occurs in certain countries. With the rapid urbanization in China, rural people increasingly come to the metropolis to find jobs and live their lives. Of its 1.4 billion populations approximately 674 million are rural people. In this group, 170-180 million are floating population who commute between village and city (National Bureau of Statistics of China, 2011). Increasing numbers of rural migrants bring their children to the cities. The number of these migrant children has reached 35.81 million in 2010 (All-China Women's Federation, 2013). 80.35 percent, 28.71 million, do not have urban hukou in the cities. Because of China's hukou household registration system, these rural migrant children are not classified as urban residents, which means limited access to education, housing, healthcare, and social security. Moreover, 72.6 percent of migrant children (25.99 million) are school-age attending school in urban centers or private migrant schools (All-China Women's Federation, 2013).

The target group of study is rural students who migrated within regions and are attending urban high schools. The imbalanced educational resources in China allow limited chances for rural students to gain urbanism until they enter urban high schools from rural junior high schools. Most of these students get rare chances to enter the city at earlier ages unless they receive a high score on the graduation examination. If so, then their exceptional record on College Entrance Examination escalates their chances of attending a decent university in the metropolis and then finding a job to stay in the city. This is a traditional trajectory these students took to change their original residential identity. This urbanization trajectory provides an escape from the ties of membership in rural-based communities. However, when leaving rural places for the metropolis, nearly all people experience culture shock to some extent as urban and rural life differ dramatically in aspects such as food, clothing, transportation, conversation, and education. They live in the margins between rural and urban culture. This phenomenon is quite typical for rural students studying in urban schools in many cities. The purpose of this study is to understand their experience in this journey. Specifically, this study is to explore what do they experience in unfamiliar places where they cannot find a sense of belonging, how do they deal with their original rural backgrounds and cultural personalities, and how do these experiences make them marginal people in the metropolis, are urgently in need of examination.

\section{Related Literature}

Differences in Rural and Urban Culture

Culture, as Simmel (1971) stated, refers to "the cultivation of individuals through the agency of external forms which have been objectified in the course of history"(p. 6). The external differences in

\footnotetext{
${ }^{1}$ Correspondence author's email: tonywong@uw.edu
} 
social structure, mode of production, and lifestyle between urban and rural places and people form different cultural norms and patterns, that are embodied as values, ideologies, and actions of people. Durkheim (1893/ 1997), in his The Division of Labor in Society, explained the concepts of "mechanical solidarity" and "organic solidarity," that stand for different kinds of social ties in rural and urban cultures. Wirth (1938) concluded urbanism as a way of life and urban personality as a reserve, blasé outlook; indifference; sophistication and cosmopolitanism; rationality; relativistic perspectives; tolerant, competitive, self-aggrandizing, and exploitative attitudes; feelings of friction, irritation, and nervous tension bred by frustration; acceptance of instability and insecurity; tolerance of eccentricity and novelty, and approval of efficiency and inventions; and marked degrees of personal disorganization. Fischer (1975) further pointed out the intensity, diversity, diffusion, and unconventionality of urban culture as the city grows.

Paralleling rural-urban culture differences in the context of China, Fei (1998), in the 1920s, identified the Chinese rural society as one based on ritual and customs (lishu, 礼数) and urban society as one based on law and reason (fali, 法理). He further described the construction of traditional and rural China as a society of cha xu ge ju (差序格局, the pattern of difference sequence) in which the social network of individuals constitutes the whole social order. Cha $x u$ ge ju captures the essentials of the current rural society in China. On the counterpart, modern city is the result of industrialization and urbanization, with market economy playing a central role. Urban differences from rural life exist in cultural traits, social structures, and life styles (Jiang, 2003). Citizen rights, laws, pluralism, and openness constitute the basic cultural characters of modern urban society (Zhang, 2005).

\section{Marginality of Rural Migrants}

The idea of marginality has been presented in social science scholarship since the early 20th century. For example, Simmel (1903) stated the difficulties of maintaining independence and individuality within modern life. Park (1928) introduced the concept of "marginal man" that in the process of migration and acculturation, migrants who strive to live in two diverse cultural groups appeared as a cultural hybrid and form a personality type where conflicting cultures meet and fuse. Du Bois (1897) also addressed marginal experience and identity as a "sense of always looking at one's self through the eyes of others, of measuring one's soul by the tape of a world that looks on in amused contempt and pity" (p. 194). Gordon (1992) further defined this situation as cultural dissonance. Stonequist (1935) elaborated this marginal personality characteristics include ambivalence, excessive self-consciousness, restlessness, irritability, moodiness, and lack of self-confidence. Bourdieu (1984)'s theory on social, symbolic, and cultural capitals explained difficulties of migrant met in a heterogeneous environment.

\section{Social Integration of Migrant Students in China}

Wang (2010) found that migrant children could consciously recognize the rural-urban difference, regarding urban impressions and urban images. Scholars such as Liang and Wang (2011), and Xiong (2009) found some rural migrants perceive urban people as cold and indifferent, and have intense feelings about the cold social environment of the city. Rural migrant students are easily personally affronted by negative stereotypes and morality. A common perception among rural migrant students is that urban people look down on rural people. They often perceive urban people as rich and rural people as poor population. Because of the lower socioeconomic status of rural population and long existing prejudices toward rural residents, rural migrant students, as rural hukou holders, are stereotyped because of their social status and economic status (Wei, 2009; Xiong, 2009).

In coping with these stereotype and discrimination, rural migrant students are sensitive to discrimination from city residents and are reluctant for others to know about their countryside background because of self-esteem. Migrant children's comments on their identification are mixed and indicated a "partial urbanization" (Liang \& Wang, 2011). These students demonstrate a coexistence and intersection of confidence and low self-esteem (Shi, 2005). Specifically, migrant children have complicated mentality combining regional involvement and social segregation, which is displayed through their strong sense of belonging to the city yet separation and estrangement from urban people. This is why some researchers describe them as drifting "duckweed-like people"(Sun, 2007), and other as living a "stranger-acquaintance" relationship (Liang \& Wang, 2011). These coping strategies and resulting identities are quite similar to the ideas of marginality as characterized by western scholars.

Values, future plan and expectations are salient topics of self-identification. Shi (2005) investigated career expectation and self-identification of second-generation urban-migrants and found that the majority of 15 cases choose to stay in the city. However, compared to urban youth, rural migrants still had lower expectations of their futures and were more pessimistic (Xiong \& Yang, 2012). 
In an ethnographical study on rural migrants in Nanjing, Wang (2010) found a gap between expectation and reality in social interaction with urban residents. They found out that they found fewer gaps in expectation and reality during interactions among rural peers.

\section{Psychological Well-being of Migrant Students}

Theoretical research on the marginal person stated and forecasted potential psychological problems, and qualitative and quantitative research has concerned the general psychological well-being and problems of migrant children. Based on the Stressor Scale for Middle-school Students and the Coping Style Scale for Middle-school Students (Qu, Zhong, Yan, \& Yang, 2008), the results showed that the stress of migrant students is more serious than that of urban students in four subtests of stressors: stress of learning, stress of home environment, stress of friendship, and stress of society culture. Similar results were also founded in other five provinces (Wang, 2009; Ye, 2008). Moreover, rural students lack of positive coping style (i.e., problem-solving, seeking support, reasonable explanation, patience, emotional display, fantasy, denial) to overcome stresses.

Shao (2011) argued that stress of learning is the primary problem of junior high school students in Grade One. Another notable pressure is from the family. Chen (2005) stated that parents' hardships from work and daily urban life strengthen their hope of change for the next generation. High expectation from parents causes pressure for rural students. Senses of belonging and insecurity have also been frequently mentioned in psychological studies of migrant children. For them, a sense of belonging to the city is far lower than that of local urban peers. While they feel more belonging to the city than to their hometown, the attachment tends to diminish as time goes by and their stay in the city increases (Sun, 2007). Migrant children have a much lower standard of self-consciousness than their urban peers, as revealed by scores on separated scales of intelligence and school conditions, behaviors, extent of happiness and satisfaction (Faltis, 2014; Guo, 2008; Shao, 2011).

As scholars inquired the formation of students' well-being, Feng (2012) found a negative correlation between family function and problem behavior of migrant children. That is to say, the better the family function, the less problem behaviors will happen. Also lower function in roles, affective responsiveness, affective involvement, and behavioral control lead to problem behaviors in rural migrant students. Pan (2012) also found the existence of bad behavior habits, which are related to family education, school education, social impact, and students' characteristics.

These studies summarize the theoretical and practical differences between rural and urban cultures that create borders for rural migrants who now live in the urban settings have to cross and how these crossing are mediated. Yet, these studies have rarely applied thick description (Geertz, 1994; Lafer, 2014) to students' substantive feelings and perceptions of rural-urban cultural differences. More studies applying cultural theories to understanding patterns of human behaviors among migrants are needed.

\section{Methodology}

\section{Research Design and Participants}

In order to gain some insights into the general psychological situation of rural students in urban schools, as well as detailed information about their marginal experience, I visited schools, observed classes, and talked with rural students after school. Visits were made to better understand how education was organized and conducted in and out of class, and to observe the learning environment and campus life. I also conducted a survey. It was designed for a self-assessment using the Symptom Checklist-90 (SCL-90). From February to June 2011, I visited 11 urban high schools in three provinces, six in Guangdong Province, four in Chongqing City, and one in Jiangxi Province. All of these three Provinces are regions where rural and urban cultures interact. A total of 57 students participated in the survey and 55 of them engaged in conversation. The conversations with the 55 students, from 16 to 19 years old, were recorded. Thirty of them were female and 25 were male; 34 were from Grade 10 and 21 from Grade 11. Each conversation took about 20 to 35 minutes.

\section{Setting and Procedures}

Guangdong Province has experienced rapid urbanization in percentages and since economic reform and open up policy in 1980s, which increased openness to the outside world. I chose six high schools in Guangdong Province to visit, according to the educational distribution in this province. Three schools were located in the central area of Guangdong Province, which offers excellent education resources and environments. Also I chose three schools in western Guangdong, where the situation is relatively limited. I assume that various schools in different regions would be reflected in the answers of students and their level of urbanization. Chongqing has been quickly developing and transferring from village to metropolis since affiliating with the central government in 1997. The 
double increase speed of GDP (the gross domestic product) than the national average brought huge changes in the economy, culture, and society. Though Chongqing is growing as a big city in public facilitation and transportation, there are still huge amount of overlapped rural people in remote area even in the city. In the process of modernization, there is a growing gap between urban and rural paces, which actually makes Chongqing an appropriate place to collect information about marginal people. Chongqing also has developed a high level urban culture in a short time, which endows it with many modern facilities. Yet there are vast areas that were rural places originally, and rural cultural patterns prevail. Thus, large numbers of people moving between these two arenas cause them to experience much tension between these different ways of living. Although Jiangxi Province is relatively poorer, it also experiences development and problems like the other two provinces.

\section{Data Collection and Analysis}

This study applied Symptom Checklist-90 (SCL-90) to get a sense of the psychological situation or distress. SCL-90 is a self-report psychometric instrument designed to evaluate psychological state and symptoms of psychopathology. The 90 items on this questionnaire include nine factors of somatization, obsession-compulsion, interpersonal sensitivity, depression, anxiety, hostility, phobic anxiety, paranoid, and psychoticism as the observational indexes. A 5-point scale for scoring of 0-4 was used, with 0 as none, 1 as mild, 2 as moderate, 3 as quite severe and 4 as severe. The results were compared with national norms of middle school students in China. All conversations in this study were conducted in Mandarin. The researcher transcribed audio recordings of talks. Following the conventions of Krippendorf (2010) and Gee (2011), the data were then subjected to textual and discourse analyses.

\section{Findings}

The result of the SCL-90 in these 11 schools, showed that rural students got higher scores on several symptoms, compared to the national average (China) of senior high school students. Rural students in these 11 schools showed higher levels of phobic anxiety, psychoticism, obsessivecompulsive, anxiety, interpersonal sensitivity, depression, paranoid ideation, hostility, and somatization. This result corresponded to another similar study using SCL-90 (Wang, 2009) in five other provinces also found that 18.73 percent of rural migrant students have mental problems. Beyond these abstract psychological symptoms, more interpretive details emerged from the talk with rural students on urban impressions, life experiences, and values.

\section{Impressions of the City and Schools}

Due to institutional disparities between rural and urban places, huge gaps still exist in facilities, traffic, consumption, and living situation. Most participants I talked never had chances to enter the city until admitted to urban high schools. A few participants did have fragments of memory of sporadic encounter with the city, such as entrance examination, travel transition, and social events. Moving to the city, rural students first noticed the surprising size of urban places. Skyscrapers, huge buildings, blocks of malls, and busy traffic make rural students realize the huge gap between rural and urban places. One student (Dan Yang, personal communication, March 18, 2011) ${ }^{2}$ described city life as "joyful, lots of buildings, luxurious places are much more than my home town. You can find Internet bars nearly everywhere compared to only one in my hometown. Also, evening here is more lively, which is not like the silence after eight clock in my hometown." The external variety was then followed by internal thrill and excitement among rural students, which also incited higher expectations of study and life. Yong Li (personal communication, May 8, 2011) remembered that he was excited and energetic about any surrounding events. Another student, Hui Qin (personal communication, May 8, 2011), said, "Because I am from rural places, when I first arrived here, the most salient feeling was curiosity for everything. I was super curious about what exactly it is."

Yet, thrill and excitement came with some other feelings. The huge size of the urban environment and complexity of urban life challenged rural students' old ways of living. For example, because of the complex bus system in Chongqing, Zen Qin (personal communication, May 4, 2011) found it really challenging to locate the right bus in the first semester. He said, "In my hometown, even though there are buses, there are only a few stations." Tin Wang (personal communication, May 4, 2011) said that she rarely went outside of school in the beginning, because "I don't even quite remember the place I had gone last time." The negative sides of the urban environment also caused dissent and phobic anxiety. For example, one student said, "The air in my hometown is much clearer and the city streets are more chaotic, and motorcycle robbery is quite terrifying" (Song Gao, personal

\footnotetext{
${ }^{2}$ To protect the privacy of students, a pseudonymous name was used in citation of chat content.
} 
communication, March 27, 2011). As impressions changed from fantasy to cruel reality, phobic anxiety became increasingly evident.

Rural students noticed obvious differences between schooling at home and in the city. One student noted "my prior school, founded only ten years, had bad facilities. We still use old wooden windows. That can't compare to the brand new steel window and computers" (Zong Wang, personal communication, March 20, 2011). In the area of software, which included the quality of teachers, education style, and learning environment, another student said, "Teachers here are excellent. Teachers here of one grade are as many as the total number of my prior small school" (Yinyin Zeng, personal communication, March 18, 2011). There are also many unexpected many situations causing panic for many of these students. For instance, the closed dormitory system makes it difficult for students to go back home except on the weekend. As one student explained, "The total closed environment limits my freedom. I can no longer go home every day like before" (Ming He, personal communication, March 8, 2011). Because of different local dialects, some students are "afraid of their bad accent" so they talk less to teachers and peers (Song Gao, personal communication, March 20, 2011). These all influenced their impressions of and responses to the urban environment and school.

\section{Study Adaption}

Both students from Grade 10 and Grade 11 reflected their adjustment problem in urban high schools. This section will describe their experience from the perspective of learning climate, learning and teaching style, learning content, and students' reaction. In city schools, a much more intensive and competitive learning environment firstly disturbed students when they started their high schools. Coming to the urban schools, all of these rural students lived in the dorm and were retained in the school for six days of a week. Learning then became the salient option for their everyday life. Shunying Liu (personal communication, May 8, 2011) said, "Students around me works harder than my previous classmates... Now, (in urban schools) I have to study hard. And I can't play and have a good time without thinking about study." Meanwhile, they are usually admitted to advanced classes, where more competitive environments exist. Some of these previous top students, "...could bone up for the exams in middle schools, and never kept notes. But here I have to be more serious" (Kai Peng, personal communication, May 10, 2011). As another student from such a class said, "Classmates around me perform pretty well. Classmates in one dormitory often compete with each other. Different from the poor performance of previous classmates (in rural school), it is really difficult and competitive to become outstanding among current classmates" (Hongying Liu, personal communication, March 18, 2011). In some ways, this competitive environment served as a stimulus for student to focus on study. But it also caused anxiety and despair when dropping from top students to average. At home schools, they were usually guided by concerned teachers in rural schools and graduated with outstanding academic backgrounds, especially high scores on senior high school entrance examinations. Yet when they enter urban high schools, they found 'teachers usually don't see you as special; classmates are well-matched; I really wanted to be top notch. After been knocked down several times', I then realize my real level and don't expect to compete with those strong, with a head broken and bleeding" (Shunying Liu, personal communication, May 8, 2011).

In the urban context that promotes speed and efficiency some students have problems studying effectively with the growing amount of high school knowledge and fast teaching pace.

One feature is the form of autonomous learning. Teaching and learning in urban high schools are more democratic, allows students more time to make autonomous goals, and to discover effective learning methods. "In the past, the teacher always watched me and urged me to study. I was not quite used to the autonomous learning in the beginning, played all the day. After seeing my grades going down, I start to worry about it and learn to study by myself" (Hui Qin, personal communication, May 8, 2011). Another student said, "Education here is closer to quality education. My prior teachers would rather assign you one thousand questions than lose one examination item" (ZONG WANG, personal communication, March 18, 2011). In this learning environment students break away from old learning methods and begin to plan intellectually their study habits based on calculating learning derived from different methods. This situation corresponds to Simmel's (1971) ideas on urbanite rationality and calculating mentality. In the question of "I feel rushed to finish learning tasks" on the SCL-90, 31\% of students choose "moderate severe", and 14\% choose "quite severe or severe".

Another adaption problem is the connection of classroom and extra-curriculum knowledge. Teaching in rural schools was reflected as sticking around textbook and high school entrance examination. Teachers in urban high school combined social events and personal experience with the textbook teaching. In this process, students get more chances to touch on the features of urban culture. English teachers introduce customs, pop music, and entertainment news from other countries. Social studies teachers embed more national or foreign events in teaching, talk more about political systems, 
and the development of the nation. Other teachers refer to current fashions, films, song lyrics and other things related closely to urban life. When asked about their responses, these students mentioned the "broad scale of knowledge, visions and even the feeling of self-multiplication" (Yanchang Huang, personal communication, March 18, 2011).

Beyond specific subject knowledge, rural students are given more life lessons on human quality, social skills and future career. "Our middle school teacher taught us based upon exam; but high school teachers taught us based upon (the development of) the whole person" (Shunying Liu, personal communication, May 8, 2011). "They taught us that in real society the ability is more important than knowledge" (Zen Qin, personal communication, May 4, 2011). "They (urban teachers) always pointed us to certain direction, and let us imagine the future development; they also planted some ideas and lead us working hard to achieve them" (Hui Qin, personal communication, May 8, 2011). An instance was given on this connection in Mathematics class.

During the Math class, we were learning the arithmetic, which relates to programing. He (Math teacher) talked to us that majoring at game design in future (college) would involve the programing. If you design a decent game, it will be make you hundreds of thousands Yuan (RMB). Even though game design is occupation for young people, it is still an admired occupation and will give you high fulfillment (Zen Qin, personal communication, May 4, 2011).

It's noticeable that teachers always set the city as setting when talking about these life lessons. I would argue that the contents they experience in city school influence them unconsciously and their future plan in urban places.

\section{Life and Leisure out of Class}

Boarding school life in the city allows rural students autonomy to manage their time and living expenses. While talking about the general situation of consumption, Kai said,

When I was young, my parents bought everything for me. I only bought some notebook for myself. They bought clothes for me. Now they are not around. I buy everything buy myself. When I feel like running out of something, I will go buy it (Kai Peng, personal communication, May 10, 2011).

One result is that the living expenses are doubled for most of students; even now the consumption is much higher than that in rural schools.

Clothing was one of the most frequently referred topics of conversation. Compared with rural life before, the youth are now more concerned about brands in clothing, through approaches like shopping in department stores or specialty stores in downtown, observing urban peers, and searching the Internet. One student said, "I was more concerned about what my mom was cooking before, but now I will spend more energy on this stuff (clothing)" (Lixie Peng, personal communication, March 10, 2011). "In the past, my mom and I often went small stores with big sale. Now I usually go to retail stores with brands when they are on sale" (Shunying Liu, personal communication, May 8, 2011). In the consumption of fashion, the peer impacts, particularly from urban peers, are changing rural students. Another girl from the same school explained, "I didn't hear of or know these logos before. But here if you don't wear them, you will not follow others' pace" (Qiuli Zeng, personal communication, March 10, 2011). Not just in southeast China, another girl in Chongqing (southwest China) has the same experience, "At first, I still have my own idea (on what to buy). But when I went shopping with them (urban peers), they will give me some advices...Then I thought wearing clothes should be for others, not just for myself" (Shunying Liu, personal communication, May 8, 2011). Yet here is significant difference between male and female participants. Female students are more eager for shopping; male students are relatively fonder of martial possessions, games, and sports.

In the area of material possessions, there are not so many differences except electronics such as telephones, MP3 players, and electronic dictionaries. The same girl (Lixie Peng) who "spends more energy on this stuff" wanted to save money for cellphone credits. Surfing the Internet by cellphone cost much more than the rates her parents paid. Logging on QQ Tencent on phone and viewing online shopping center were favorite activities of many girls after class, and even in class. One student said that a frequent topic discussed among friends is new cellphones and cellphone cases. One student (LNJ, personal communication, March 12, 2011) owned a series of electronics even though his father was unable to work after a car accident. When asked about the purpose of purchasing, he explained it was for study convenience. But when probed about the frequency of use, he said frankly that he just wanted to try it after watching others using them. 
Regarding entertainment and leisure, urban leisure choices among girls included hanging out in bookstores, skating, KTV, watching films, listening to music, and barbecuing. Leisure choices from boys are sports like basketball, badminton, and Internet games. Two boys favored nunchakus and street dancing. Thus, being away from original rural environments and entering urban settings led to significant changes in the style of entertainment. The joy of the farms and related fun activities are not available for students. When learning new customs and habits of daily life, city and urban environments educate or seduce these youth into the deep core of urban spirit and culture.

Still, life out of class is still relatively monotonous and uneventful for high school students due to high-stakes standardized test. During weekdays, they need to get up and study from 7 A.M., and stay up until 9 or 10 P.M. Rural migrant students usually have one day plus one night as "weekend". During the weekend, they went out for a half day, and then stay in campus for the rest of weekend. This also explains why some of students didn't feel big difference on life out of class between the past and now. Moreover, few students in this study didn't have the same longing for town bustle and feel connected to the consumer culture. "When standing on the street, I saw people busy around. Still I am feeling alone by myself, which made me very uncomfortable. It's a feeling of being a misfit" (Hui Qin, personal communication, May 8, 2011). Being a misfit, more or less, appears among these rural students. And there is no significant difference between grade 1 and grade 2 in the area of leisure and after-school life.

\section{Social Interaction}

Social interactions referred mainly to students' interactions and relationships with urban and rural peers and teachers. Frequent occurrences of interpersonal sensitivity in the SCL-90 indicated the problems rural students encountered with communication. In answering the questions "Others don't understand and be patient" and "I feel others are unfriendly to me" $26 \%$ and $20 \%$ of the students respectively agreed "moderately" or "extremely". When talking about the challenges of communicating with urban peers, rural students reflected that they feel unfamiliar, uninterested or uncomfortable on the content of conversation. One student (Tin Wang, personal communication, May 4, 2011) said,

They (urban peers) are from urban areas (in Chongqing), and can go home frequently. Then they could surf the Internet, watch some news, social events, or something new, which we knew less... I rarely participated the conversation with those classmates. Because I was not interested in what they were talking about. It's always about films, or games.

For some students that tried to engage still found that the lack of news resources like Internet and TV made it difficult to speak. One girl said, "When chatting with them, they often use buzzword that I do not understand. This makes it difficult for me to engage (the conversation)" (Fengrui Yang, personal communication, March 18, 2011). Another girl indicated her preference of communication with previous classmates in rural schools. She said,

When I came here, my clothes and talking styles were always mentioned. Take my neighbor as an example. She often told me how rich her family is and how much her shoes cost, and she always thought she should be looked after" (Lixie Peng, personal communication, March 10, 2011).

Communication difficulties between urban and rural youth often involve shopping, fashions, and entertainment. When talking about these topics, the rural students experienced feeling of marginality. These social difficulties are connected mostly to economic background. It is less problematic to communicate about study motivation and future plan, and communication problems and similar learning objectives in the same school environments. Some rural students further interpret their preference of peers of rural backgrounds although the percentage of rural to urban students is extremely unbalanced (there are many more urban than rural students in their schools). Hui Qin (personal communication, May 8, 2011) said, "We have many things in common. Umm, that is to say, what we know is pretty much the same. But when I hanged round with my urban friends, I felt a little bit inferior." By going home together, visiting, and talking on the telephone, they stay in contact with new and old friends in or out of the same class and school.

But also there were some students who feel less difference on interacting with rural and urban peers. One student reflected, "I make my friends not based on where they are from. As we got along with each other longer, we established our relationship and then we became friend"(Tin Wang, personal communication, May 4, 2011). Few students preferred interacting with urban peers. "Umm, this might be a little selfish. But my feeling is that my peers from rural area are tense and reserved; my 
peers from Chongqing City are more nature and at ease" (Shunying Liu, personal communication, May 8, 2011).

Another notable finding is on the ways of social interaction. Living in the urban social network and dealing with urban peers formed impacts on rural students' way of social interaction. They made more friends through social network, rather than meeting and making friends by individual. Kai Peng (personal communication, May 10, 2011) reflected, "My group of friends is getting broader. I was making friends just by my network, but now by going out with other classmates, I met friends who are friends' friends." Different social events also allow rural students a different way to look at social relationships. "We now are progressing our relationship in events. This is not like when we were in middle school, we judged people just based one or two things and then never changed. Now we are looking at one person through different aspects" (Shunying Liu, personal communication, May 8, 2011). Moreover, the rational characteristic of social relationship is also changing rural students. After she entered high school, Tin Wang improved a lot with her temper. She said, "The climate is harmonious, I don't want to lose my temper and embarrass myself' (Tin Wang, personal communication, May 4, 2011). Kai Peng became more cautious in talking. He said, "When we have more unfamiliar, (it's not easy) to comment on others. The spoken comment might offend others" (Kai Peng, personal communication, May 10, 2011).

Most rural students feel some anxiety about interacting and relating with teachers, and they choose to work on their own to solve learning problems. When studying in small rural schools and communities, there are many opportunities for students to meet, talk, and interact with others, including teachers. They also receive more attention and caring from teachers and compliment for good academic performance. One student in Suixi City said, 'In junior high school, I often went to my teacher's house to have dinner, and chat with him. Now I do not have this opportunity because they (teachers) leave immediately after class" (Qiuli Zeng, personal communication, March 10, 2011).

In the area of school activities, after long-time effort on quality education and cultural and sporting activities in city schools, these become a part of rural students' lives. For example, one high school in Taishan City, with many talented students enrolled in arts and sports, holds annual basketball, singing, speaking, and dancing competitions. A more wealthy and elite high school in Zhuhai City has many student associations and related activities that offer students opportunities comparable to college level. At this school, rural students can participate in activities outside of school through events like "Mini United Nations Conference". While ample school activities do offer rural students more chances to assimilate into urban life, the fear, low self-esteem, and lack of comprehensive abilities and experiences can lead to low participation rate by rural students in these activities, compared to urban students who received quality education and grow up with many talents in urban schools.

\section{Roles and Relationships}

Status at home and school often reflect double consciousness for rural students in urban schools. One student said, "When I go home sometimes in the weekend, I feel I totally become another person. The difference is quite big" (Yanchang Huang, personal communication, March 20, 2011). For most rural students, this is the first time they have lived in a dormitory, and they can only go home once a week or even less frequently. Less time spent with families causes strangeness and distance. Students try to be more polite and cautious and get along with parents using social skills they learned from the city. One student said, "Because I get less time at home, I try to be kind and fight less" (Hongying Liu, personal communication, March 8, 2011). They talk less and chose not to go in detail about the growing differences in values and concerned topics of parents. One student said, "I am lively outside (at school), but at home I totally become silent. Even though I say something to them (parents), they can not understand me so I usually choose to say nothing" (Qiuli Zeng, personal communication, March 10, 2011). Some students also mentioned the occurrence of quarrels with family members. One student said, "I become irritable at home. They don't understand what I am talking about. We argue even over little issues" (Yiyi Liu, personal communication, March 18, 2011).

Yet some other students stated that home protects them from the outside world and brings comfort. A relaxed and comfortable environment and familiar local language make them feel more affiliated and centralized. One student said, "I never thought dormitory is a real place for living." Another one said, "Issues in campus life are always magnified, but I don't need to think about anything at home" (Yanchang Huang, personal communication, March 18, 2011). Either situation shows an obvious need to transition between home and school. One student reflected, "When studying at school, it's so intensive that time at home makes me totally relaxed" (Zong Wang, personal communication, March 20, 2011).

Relationships with classmates and peers in hometowns become apathetic, although the individuals stay in touch. Sometimes the students hang out with old friends, catch up on recent life, and 
exchange feelings during home visits. One student said, "We also went back to my prior school to see our teacher to talk and have fun" (Shuyi Zeng, personal communication, March 18, 2011). However, when chatting with prior friends, common topics became less and less because of the difference in study environment and derived values and thoughts. Another student mentioned that, "After studying at urban school, I became a silent girl and talked least at old friends' gatherings, which is totally different from my talkative self" (Yiyi Liu, personal communication, March 18, 2011). The apathy between these urban transplanted students and people in their rural hometown even turned into disdain in some ways. One student said, "People in my hometown were quite casual and careless. Boys and girls played together with bare feet on dirty ground. I could not imagine how they could behave like that and then just want to stay alone. This feeling and behavior keep me marginalized from this group" (Dan Yang, personal communication, March 27, 2011).

\section{Values}

Attempts of fitting in were frequently in the conversations. One student said, "When you go to a different environment, you will always try to engage. Hearing from them (urban students), I will try and accept it gradually. Then I found that I became more and more different from the past" (Yanchang Huang, personal communication, March 18, 2011). Another student said, "Friends and families in my hometown say my behavior and talking are unlike before, and that I am becoming a Suixi [a small city in Guangdong] person" (LLP, personal communication, March 10, 2011). Contacting and dealing with affairs more broadly and frequently, rural students in cities gradually become rational, well-planned, mature, sensitive, and anxious. The migration from natural and homogenous rural environments to chaotic and heterogeneous urban environments, makes them "know more and think more deeply and broadly, and realize things are not as simple as imagined", and also "causes them to perceive more and compel themselves to be psychologically mature" (Dongqiang Li, personal communication, March 27, 2011). This transformation also brings more troubles and challenges. One student said, "After coming to the city, I got everything in my life to worry and to be anxious about. Issues and problems here are always magnified, and push you to be more sensitive and cautious" (Yanchang Huang, personal communication, March 18, 2011). In the process of so called "growth", rural students experience the personality of rationality, calculation, and sensitivity, which increase the spirit of urbanism and modernism.

In urban schools and societies, more attempts to go beyond old and traditional thoughts occur every day and in planning for the future. One student recalled, "I always thought it will be easy to live a happy life going outside (of rural places) and finding a job, but experiences here tell me it is really quite hard to do that" (Yong Hu, personal communication, March 12, 2011). Yet the students still believe "knowledge offer chances for a better life" (Huidi Chen, personal communication, March 13, 2011). One student said, "I work harder than ever. Life in Shenzhen pushes me to study hard and then go to an excellent university. Because fault in even one step will ruin the next one and drive you away from your original expectation" (Dan Yang, personal communication, March 27, 2011). New acknowledgements and definitions of success and talent in modern society are developed. Some students create broader visions for considering the future.

Most rural students' traditional plan is to achieve well in competitive study through junior high school, senior high school, and college. Yet a small portion of them realize "learning at school and graduation examination to college are not the only way for the future" (Shuyi Zeng, personal communication, March 18, 2011). Some students stated that, "Urban high school life makes many things clear to me, help me understand multi-criterion for excellence, and leads me to focus more on comprehensive competence than mechanical study" (Zihai Chen, personal communication, March 10, 2011). Another student explained, "My whole plan in life before is to be a good student with a good record, but now I prefer to be a writer or musician, which is more interesting and funny" (Yang Li, personal communication, March 27, 2011). According to these statements, the future is perceived more broadly, and social life is more vibrant.

Broader and closer connections with urban life also bring negative influences. When facing numerous and complicated choices, some students get lost, some students practiced their choice and plan with hope, others experience repeated disappointments, and some or depressed and marginalized. Trying their fortune in the metropolis sometimes turns into the disappointing conclusion that the "the big city is not so good; people there are so hypocritical" (Zihai Chen, personal communication, March 10, 2011). Caught in the margins between an imagined ideal and cruel reality, stuck between a rural background and urban education, these students sometimes even wondered if they were schizophrenic" (Xieyu Huang, personal communication, March 10, 2011).

\section{Discussion}




\section{Fluid Identity}

For the internal features among these students, included heterogeneity regarding grade, gender, age and family background, Sue and Sue's model of cultural identity helped in understanding the status of students in the conversation. Sue and Sue (2013) identified the first three stages of cultural identity development as conformity, dissonance, and resistance and immersion. The stage of conformity in this project means rural students show a strong preference for the values, beliefs, and features of urban environment and culture over their own. Rural students also have negative attitudes toward themselves and their own group. In the stage of dissonance, rural students encounter information that contradicts their values and beliefs. During the stage of resistance and immersion, rural students completely embraces rural culture and rejects the dominant urban culture, and are inspired to find out more about their own cultures forming a stronger connection to their own groups. These three stages ideally describe linearly the identity developmental characteristics of rural students. However, the real development of cultural identification is fluid between stages and even intersected on different aspects of identity. That is, the current status of rural students is not solely on any stage. They are hybrid features of different stages depending on aspects of identification such as urban impression, study, leisure, and values.

\section{Complex Feelings during Migration}

It is natural for feelings to emerge as people move into new places, and people begin to adjust to difference between their previous and current environment. Corresponding to Sue and Sue's model (2013), students from 10th grade show more features attached to the stage of conformity as they just enter the city. Students from 11 th grade start to reflect more features close to the stage of dissonance. To put the process in perspective, the prior imagination of the beautiful city is now in front of rural students. They feel surprised and excited by, and interested in the vivid urban life. However, after the excitement challenges of the city come, such as environmental problems and social safety. Still stereotypical conclusion is hard to make on rural students whether their excited about the city originally come from the urban environment or just from novel environment. Moreover, the feeling of excitement correlates positively with socioeconomic gap between hometowns and current cities. Students from wealthier or more developed towns felt less surprised and had more realistic impressions of the city. There were no obvious differences between male and female students.

\section{The Impacts of Socioeconomic Status}

The talks with rural students revealed differentiation among them even within this rural catalog. For the external environment, these 11 schools are located in cities with different socioeconomic levels. Also the rural students came from rural places with differentiated socioeconomic levels. The contexts for these adaption problems are related to family background, students living in the city who have better economic status, clothing, and broad experiences for communication use form subtle pressures on rural peers; influence from the metropolis create huge gap in views, values, and life styles; and local village accents are considered less desirable than city communication styles (for example, the Leizhou accent is ridiculed and made fun of by city dwellers). But it is also noticed that as students stay longer in the city, they felt less sensitive and more engaged in social interaction. As one students from second grade said, "when I first came here, I didn't talk much with strangers. In the beginning, I felt like I was like a non-existent person; no one would notice me. Now I am getting more optimistic and cheerful"(Hui Qin, personal communication, May 8, 2011).

\section{Conclusion}

Rogoff (2003) stated that individuals develop as participants in their cultural communities, engaging with others in shared endeavors and building on cultural practices of prior generations. Students who grew up in rural environments and urban environments show differences in cultural psychology. As rural students receive more education in urban schools, their social class mobility increases. This confrontation reflects the perceptions of rural students about cultural differences. In order to adapt into urban life, rural students continually assimilate to urban life and urban culture and start their odyssey of urbanization. The feeling of surprise, excitement, low self-esteem, loneness, and rationality enrich their experiences and become part of their personality. Yet, urban lifestyle and cultural personality acquired by rural students do not match their socioeconomic positions. As the Chinese Academy of Social Science (2004) reported, economic resources, institutional resources, and cultural resources are being aggregated to higher social class. Obstacles for social mobility are being strengthened, and individuals from lower socioeconomic status are finding it more and more difficult to gain access to the middle social class. Stuck between rural and urban cultures, rural students experience marginality when they do not want to go back to rural life but find no deep grounding in current urban 
life. This project revealed, complicated marginal feelings and marginal personalities among rural students.

Even though reality of solidification in social mobility, there is still possibility for rural students to develop some agency while transiting between rural culture and urban culture. During the process of adapting to urban culture, rural students provide new lens for both rural people and urban people to understand each other. Education plays a role in guiding these rural students when they enter the city and assimilate into urban life. Culturally responsive curriculum and teaching should be developed to help students adapt to urban life and explore more critically who they are, where they come from and where they are going. Influences on their current education and life in urban high schools, and rational self-identification in cultural transition are important during higher education and society life; both should be analyzed more thoroughly. Moreover, curriculum should develop for these culturalboundaries-crossers to facilitate mutual understanding between rural culture and urban culture.

\section{References}

All-China Women's Federation. (2013). Woguo nongcun liushou ertong chengxiang liudong ertong zhuangkuang yanjiu baogao [Report on rural left-behind children and migrant children]. Retrieved from http://acwf.people.com.cn/n/2013/0510/c99013-21437965.html

Bourdieu, P. (1984). Distinction: A social critique of the judgment of taste. London, UK: Routledge.

Chen, M. -F. (2005). Wailai wugong zinv renge tezheng de yanjiu. [A research on the personality characteristics of migrant laborers' children.] Psychological Science, 28 (6), 178-180.

Chinese Academy of Social Science. (2004). Dangdai zhongguo shehui jieceng yanjiu baogao. [Report on social stratification in current China.] Retrieved from http://www.sociology.cass.cn/pws/lichunling/grwj_lichunling/P020041222488561878219.pdf

Du Bois W. E. B. (1897). Strivings of the Negro people. The Atlantic Monthly, 80(478), 194-198.

Durkheim, E. (1997). The division of labor in society. (L. Coser, Trans.). New York, NY: Free Press. (Original work published 1893).

Faltis, C. (2014). Toward a Race Radical Vision of Bilingual Education for Kurdish Users in Turkey: A Commentary. Journal of Ethnic and Cultural Studies, 1(1), 1-5.

Fei, X. -T. (1998). Xiangtu Zhongguo Shengyu Zhidu. [Soil China Fertility System]. Beijing, China: Peking University Press.

Feng, S. -D. (2012). Shehui zhichi zai liudong ertong de jiating gongneng yu wenti xingwei zhijian de tiaojie zuoyong. [Accommodation of social support in migrant children's family and problem behavior.] Educational Measurement and Evaluation, (5), 40-43.

Fischer, C. (1975). Toward a subcultural theory of urbanism. American Journal of Sociology, 80(6), 1319-1341.

Gee, J. P. (2011). How to do discourse analysis: A toolkit. New York, NY: Routledge.

Geertz, C. (1994). Thick description: Toward an interpretive theory of culture. Readings in the philosophy of social science, 213-231.

Gordon, E. (1992, April). Building on and integrating cultural diversity: The case of African Americans. Paper presented at National Conference on Educational Reforms and At-Risk Students Proceedings, Palo Alto, CA.

Guo, J. -H. (2008). Mingong zinv ziwo yishi zhuangkuang jiqi jiating jiaoyang fangshi de xiangguan yanjiui. [Correlations research on self-awareness and family rearing pattern of peasant workers' children]. (Unpublished master's thesis). Nanjing Normal University, Nanjing, China.

Jiang. L. -H. (2003, November). Chengshixing yu nongmingong de chengshi shiying. [Urbanism and adaptability of rural migrants to cities.] Social Science Research, 92-96.

Krippendorf, K. (2010). Content analysis: An introduction to its methodology. Thousand Oaks, CA: Sage.

Lafer, S. (2014). Democratic Design for the Humanization of Education. Journal of Ethnic and Cultural Studies, 1(1), 6-12.

Liang, Z. -L., \& Wang, Y. -J. (2011). Liudong ertong chengshi yinxiang yanjiu: Yi 63 fen fangtan ziliao wei zhuyao canzhao. [A study of migrant children's city impression: Take 63 interviews for instance.] Journal of Hohai University (Philosophy and Social Sciences), 13(3), 41-47, 9091.

National Bureau of Census. (2011). Diliuci quanguo renkou pucha zhuyao shuju fabu. [Brief report on sixth national population census of the People's Republic of China.] Retrieved from http://www.stats.gov.cn/ztjc/zdtjgz/zgrkpc/dlcrkpc/dcrkpcyw/201104/t20110428_69407.htm

Pan, L. -F. (2012). Nongcun wailai wugong renyuan zinv xingwei xiguan paicha yanjiu [Research of 
the behavior deviation of children of migrant workers in rural junior high schools]. (Unpublished master's thesis). Suzhou University, Suzhou, China.

Park, R. E. (1928). Human migration and the marginal man. The American Journal of Sociology, 33(6), 881-893.

Patton, M. Q. (2002). Qualitative research and evaluation methods. Thousand Oaks, CA: Sage.

Qu, W. -G., Zhong, Y. -P., Yan, L. -S., \& Yang, S. (2008). Chuzhongsheng nongmingong zinv xinli yali ji yingdui fangshi yanjiu. [A research on the stress and coping style of the migrant laborers'children in city junior middle schools.] Chinese Journal of Clinical Psychology, 16 (6), 588-590.

Rogoff, B. (2003). The cultural nature of human development. New York: Oxford University Press.

Shao, N. (2011). Wailai wugong renyuan chuyi xue sheng ziwo yishi he zizun de xiangguan yanjiui. [The correlation research on self-concept and self-esteem of unofficial rural labor settlers' children of junior high school in grade one]. (Unpublished master's thesis). Suzhou University, Suzhou, China.

Shi, B. -N. (2005). Chengshi bianyuanren: Jincheng nongmingong jiating jiqi zinv wenti yanjiu [The urban marginalized: Research on migrant family and their children]. Beijing, China: China Social Sciences Press.

Simmel, G. (1971). On individuality and social forms. (Edited by D. N. Levine). Chicago, IL: University of Chicago Press.

Stonequist, E. V. (1935). The problem of the marginal man. The American Journal of Sociology, 41(1), 1-12.

Sue, D. W., \& Sue, D. (2013). Counseling the culturally diverse: Theory and practice. Hoboken, NJ: John Wiley \& Sons.

Sun, Y. -L. (2007). Wailai wugong renyuan zinv rongru chengshi de xinlixue yanjiu. [Psychological analysis of the city engagement of exotic employed personnel's children]. (Unpublished master's thesis). East Normal University, Shanghai, China.

Wang, F. (2009). Wusheng bufen diqu nongmingong zinv xinli jiankang diaocha. [Survey and analysis on mental health of the children of peasants in some regions of five provinces.] Social Psychology Science, 101(24), 56-59.

Wang, Y. -J. (2010) Liudong ertong yu chengshi shehui ronghe. [Social integration of migrant peasant's children into the city]. Beijing, China: China Social Sciences Press.

Wei, Y. (2009, September). Jincheng nongmingong zinv jiaoyu gongping wenti de tantao. [Education equity of rural migrant workers' children.] Journal of Guangxi University (Philosophy and Social Science), 31, 83-84.

Wirth, L. (1938). Urbanism as a way of life. The American Journal of Sociology, 44(1), 1-24.

Xiong, Y. -H. (2009, February). Chengshihua de haizi: Nongmingong zinv de chengxiang renzhi yu shenfen yishi. [The children of urbanization: The rural-urban awareness and self-identity of migrant workers' children in contemporary China.] China Rural Survey, 2-11, 45, 95.

Xiong, Y. -H., \& Yang, X. -G. (2012). Xuexiao leixing dui nongcun zinv jiazhiguan yu xingwei moshi de yingxiang. [Impacts of school types on values and behavior patterns of migrant children: An empirical research in Shanghai.] Youth Studies, 1, 71-82, 96.

Ye, W. -L. (2008). Nongmingong zinv xiaoxuesheng buliang qingxu tedian jiqi ganyu yanjiu. [The feature of farmer-workers' children's negative emotion and its intervention research]. (Unpublished master's thesis). Shanghai Normal University, Shanghai, China.

Zhang, X. -J. (2005). Chengshixing yu xiandai chengshi wenhua tezheng. [Urbanism and the cultural characteristics of modern city.] Journal of Tianjin University (Social Sciences), 7(3), 226-230. 